\title{
Study on Diagnosis and Treatment Technology of Cracks in Consolidated Continuous Box Girders of Middle Piers during Construction
}

\author{
Guan Liangyong ${ }^{1}$, Dong Shuiying ${ }^{2}$ \\ 1. Jiaxing Transportation Investment Group Co., Ltd., Zhejiang, Jiaxing 3140501 \\ 2. Beijing Gongke Guqiao Technology Co., Ltd., Beijing 10088
}

\begin{abstract}
In this paper, taking the cast-in-place reinforced concrete continuous box girders of a bridge as the research object, we studied the cracking type of the box girders and their construction. Combined with the calculation and analysis of the construction, the causes and effects of the cracks of box girders during the construction were further studied. Then the maintenance and strengthening scheme that UT10 super-highperformance concrete should be used on the bridge floor was proposed, which will provide reference for the diagnosis and treatment of similar bridge structures.
\end{abstract}

\section{Introduction}

In the process of bridge construction and use, the cracks of concrete structure often perplex bridge engineers and technicians, because they will affect the whole acceptance check. Sometimes even a do-over would happen, therefore, it's really crucial and necessary to find out the cause of cracks and work out reasonable plans, which can also provide reference for similar projects in the future. In this paper, taking the transverse cracks in the top section of the box girders and the flange plates as well as the Ltype cracks in the bottom plates and web plates of the midspan piers as the samples, we analyze the causes of the cracks in the box girders, and then put forward the measures for repairing these cracks to achieve the simple and effective repair for the box girders.

\section{Overview of the Bridge}

The superstructure of the bridge is made up of cast-inplace reinforced concrete continuous box girders with a combined span of $2 \times 18 \mathrm{~m}$, and the length of the bridge is $50 \mathrm{~m}$. The box girder is made of C40 concrete with single box and single chamber, and the height of the beam is $130 \mathrm{~cm}$. The substructure of the bridge is made up of column piers, consolidated by piers and beams. The pier columns, abutment caps, back walls, abutment bodies and retaining blocks are made of $\mathrm{C} 30$ concrete. The abutment is arranged radially, and U-type pile foundation is adopted. And the length of the slab behind the abutment cap is $8 \mathrm{~m}$. The plane of the bridge is located in the right circular curve of radius, $67 \mathrm{~m}$, and the longitudinal slope of the longitudinal section is $3.814 \%$. The bridge deck has a net width of $7.5 \sim 8.94 \mathrm{~m}$. The leveling layer is made of $8 \mathrm{~cm}$
C40 concrete while the bridge deck is made of $10 \mathrm{~cm}$ bituminous concrete. The waterproof layer is made of SBR (modified emulsified asphalt water seal layer); GPZ(II)-2.5-DX basin bearing is used. Model D60 is used as reference for the expansion device for the bridge. Vehicle load class of the bridge is highway-I. The elevation and I-I section of the bridge are shown in Figure1 and 2.

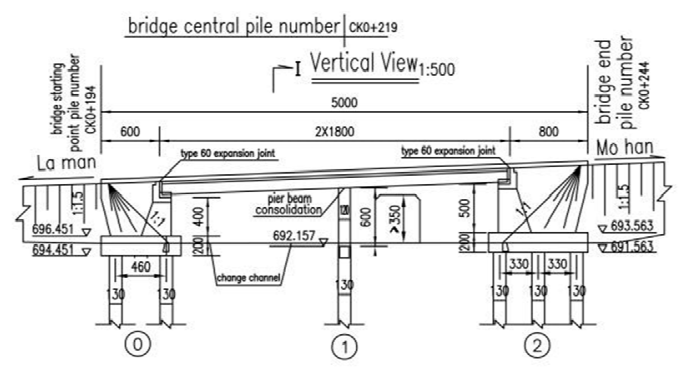

Figure 1. Vertical View (Unit: cm)

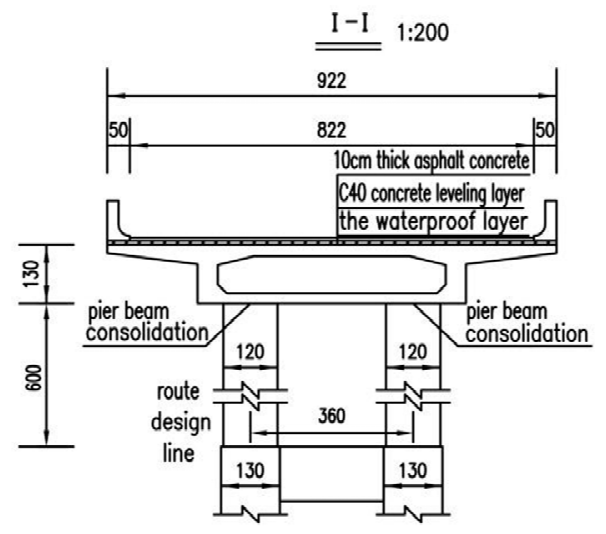

Figure 2. Cross-section Diagram (Unit: $\mathrm{cm}$ ) 


\section{Construction Procedures and Cracking Status of Box Girders}

\subsection{Construction Procedures}

The bridge is constructed with full supports, and the detailed process is as follow: pouring the ground where the bridge is located ( 6 days) $\rightarrow$ setting up the socket-type steel pipe supports ( 5 days) $\rightarrow$ accepting the supports ( 1 day) $\rightarrow$ pouring the concrete of the bottom plates and the web plates ( 6 days) $\rightarrow$ pouring the concrete of the wing plates and the roof plates $\rightarrow$ removing the box girder formwork (28 days) $\rightarrow$ removing the socket-type steel pipe supports (30 days)
The transverse cracks mainly appeared at the top of the piers and in the flange plates. Besides, the transverse cracks also appeared in the bottom plates near the midspans while the vertical cracks appeared in the web plates. The view of cracks can be seen as Figure 3. There are six transverse cracks at the top plate of the box girder on the top of No. 1 pier, one of which is 5 meters long, the other five 9.2 meters long. Moreover, there're seven transverse cracks in the left flange plate and nine cracks in the right flange plate, the length of which is between 1.0 meter and 1.7 meters. There are nine cracks in the middle web of the two midspans, which extended to the bottom plate with the L shape. The width of the maximum crack is $0.20 \mathrm{~mm}$, while the depth of the cracks is between $14 \mathrm{~mm}$ and $48 \mathrm{~mm}$. The photos are shown in Figure 4.

\subsection{Cracking Status of Box Girders}

The cracks appeared in the box girders when the sockettype plate-and-buckle steel pipe supports were removed.

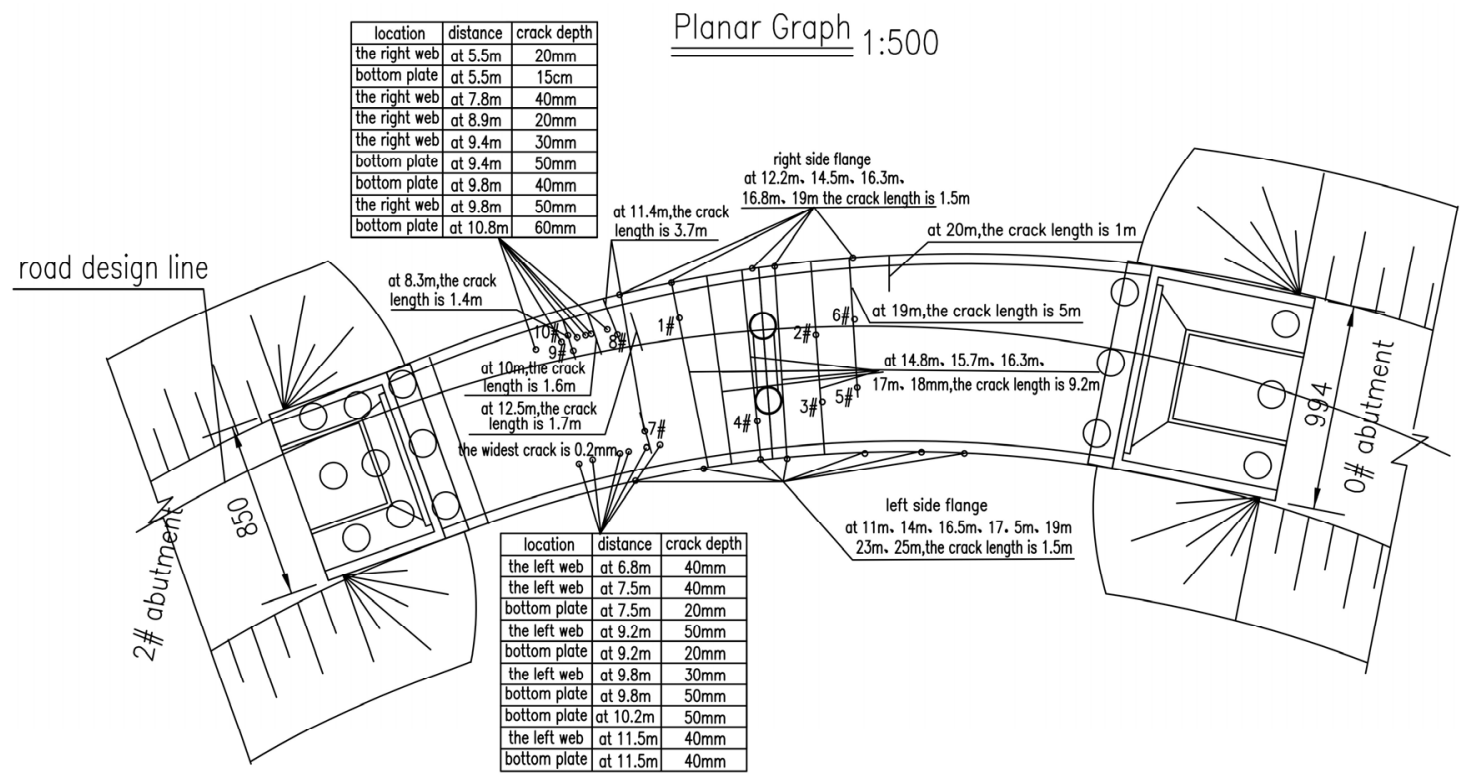

Figure 3. Diagram of the Cracks

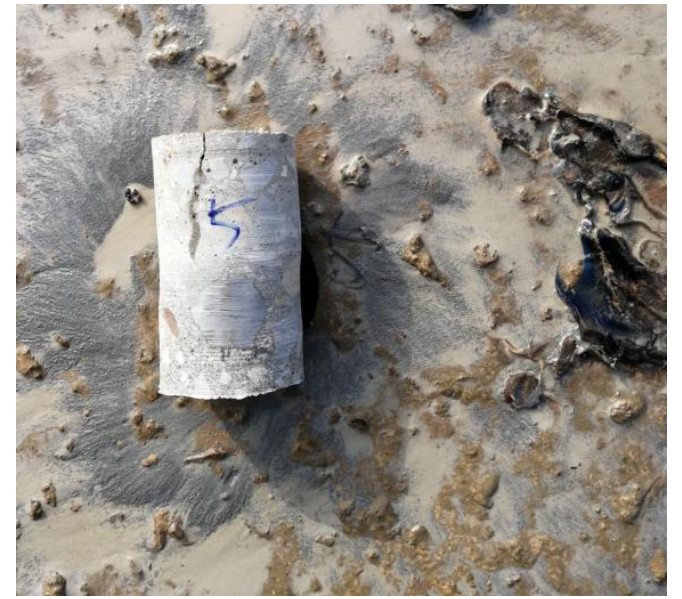

Figure 4. Diagram of the Crack Depth of No. 5 Hole

\section{Back Analysis of the Bridge Construction}

According to the calculation, the stress during the construction can meet the requirements. The bending and shear capacity of the box girders which were originally designed can meet the requirements of the design code. The crack width and the long-term deflection of the main girders can meet the requirements of the code when the bridge is used in limiting cases ${ }^{[1,2]}$ (frequency combination, quasi-permanent effect combination and standard combination). A numerical calculation model of the bridge is established to analyze the causes of cracking of box girders during construction. Taking the settlement of the supports into account, we conduct the back analysis of the construction. 
(1) Parameters of the calculation of the model: C40 concrete is used for the concrete box girders as well as the piers. Common steel bars are HPB300 and HRB400 ones. Support settlement (construction record): the settlement of $1 / 4$ of the span supports is $3 \mathrm{~mm}, 1 / 2$ of them $5.8 \mathrm{~mm}$, and $3 / 4$ of them $3.8 \mathrm{~mm}$. The temperature is considered as: temperature rises $20^{\circ} \mathrm{C}$ or it drops $20^{\circ} \mathrm{C}$; The temperature gradient: according to Article 4.3.12 of the specification (JTG D60-2015), the temperature rise of the top of the beam is $\mathrm{T} 1=25{ }^{\circ} \mathrm{C}$ and $\mathrm{T} 2=6.7{ }^{\circ} \mathrm{C}$, and the inverse temperature difference of vertical sunlight equals to it multiplying -0.5 . The stiffness of the supports is $1 \times 10^{7} \mathrm{kN} / \mathrm{m}$. The numerical model is shown in Figure

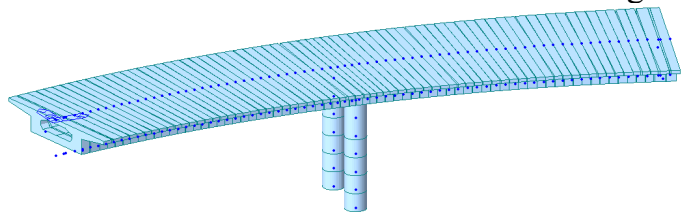

Figure 5. Numerical Calculation Model
(2) Load combination: Stress calculation of the bridge components is carried out according to transient conditions in the construction stages such as fabrication, transportation and installation. And it's adopted according to "The Code for Design of Reinforced Concrete and PreStressed Concrete Bridges and Culverts" (JTG 33622018).

(3) Construction stages: There are four stages of the construction, which are: building pier columns $\rightarrow$ setting up superstructure of the full supports $\rightarrow$ support and beam settlement $\rightarrow$ removal of the supports.

(4) Calculation results: The calculation results of removing the supports are shown in Figure 6 and 7. It can be seen from the figures that the maximum positive stress of the upper section and the maximum stress of the lower section of the box girder (at the top of No. 1pier) are $1.69 \mathrm{MPa}$ and $5.23 \mathrm{MPa}$ respectively when the supports are removed in the fourth construction stage near the midspan.

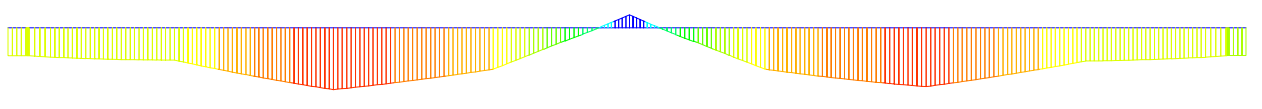

Figure 6. Positive Stress at the Upper Side of the Beam When the Supports Are Removed
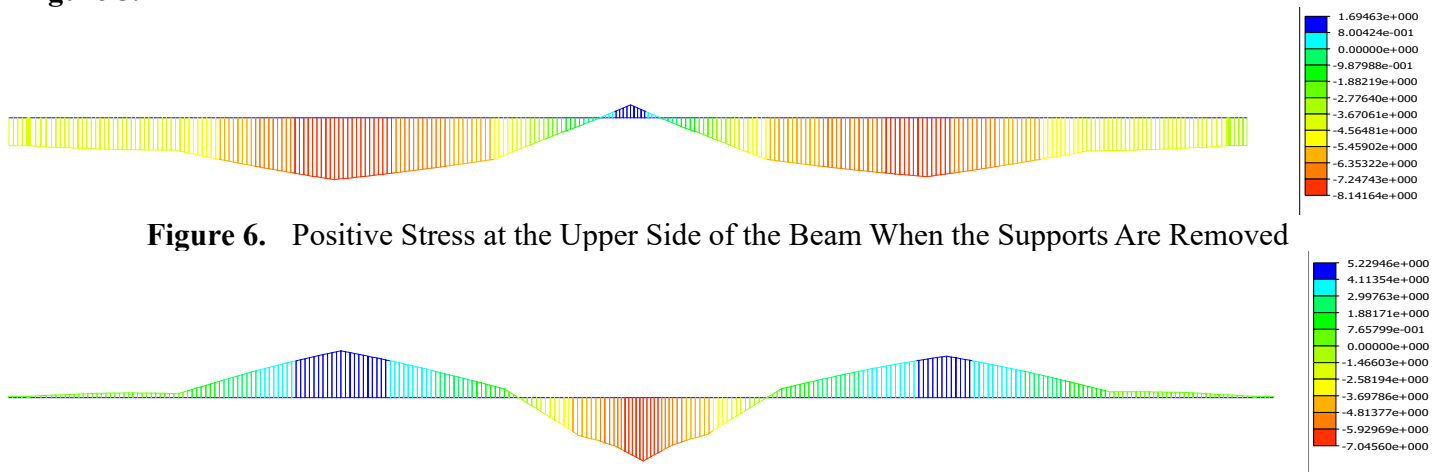

Figure 7. Positive Stress at the Lower Side of the Beam When the Supports Are Removed

According to the combination of 1.0 permanent action (without the second-phase load) that the temperature gradient is +0.8 and the whole temperature will be increased and decreased, how the cracks will be in construction stage is checked and calculated. The results show that the maximum crack width of the upper edge of the structure is $0.26 \mathrm{~mm}$, at the top of No.1 pier. And the maximum one at the lower edge is $0.27 \mathrm{~mm}$, near the midspan, which is $0.20 \mathrm{~mm}$ larger than the crack width limit ${ }^{[3]}$.

\section{Analysis on the causes of the cracks and Their Lingering Effects ${ }^{[4,5,6]}$}

\subsection{Analysis on the Causes of the Cracks}

The location and trend of the cracks in the box girders are obviously related to the disadvantageous position of bending force under dead load, which indicates that the cracks are bending force cracks. When bending force cracks are produced in the structure, it is always related to load effect and structural resistance.

(1) As for load effect: The dead weight of the structure has not changed, but the boundary conditions have changed during the construction of the structure. No cracks have been found during the course of removing the formwork of the bridge. However, cracks have been found during the removal of the steel pipe supports. The inversion results of the construction show that the structure has a good stress state when there're full supports, but the stress state is unfavorable when the structure system is changed. The internal force is redistributed when the structure is changed into a continuous system to bear dead load, which results in stress cracks in the structure.

(2) As for structural resistance: The superstructure of the bridge is poured in two times. It was poured for the first time on January $28^{\text {th }}, 2018$, the second time on February $4^{\text {th }}, 2018$. The time interval between the first and second pouring is long, so there is a time difference. Due to that, unsynchronized shrinkage of concrete occurred, which might affect the integrity of the structure. Furthermore, the reduced integrity will affect the stiffness and bearing capacity of the structure.

\subsection{Lingering Effects of the Cracks}

The analysis on crack causes shows that the typical cracks of the bridge are stress ones which occur when the structure bends under dead load. The occurrence of these stress cracks indicates that the stress of the concrete has exceeded its tensile strength. When the steel bars share the stress, it will have the following effect on the structure: 
(1) Since the tensile strength of steel bars is obviously higher than that of concrete, the possibility of further development of the width of the cracks is small.

(2) The cracking of reinforced concrete structure will reduce the bonding between steel bars and concrete. When the bonding is reduced, the number of cracks will increase more easily under the same load. Therefore, the number of cracks may further increase when the bridge is under the second-phase construction with dead load.

(3) The structural stress exceeds the tensile strength of concrete while the reinforcement stress increases, which indicates that the safety of the structure decreases.

(4) When cracks appear, the steel bars wrapped up the concrete are prone to contact with air, and they will corrode more easily, leading to the loss of the durability of the structure.

\section{Maintenance and Reinforcement Plans}

Based on the analysis on the causes of the cracks in box girders and their lingering effects, the repair and reinforcement plans are carried out from three aspects: the repair of concrete cracks, structural durability and structural safety. The detailed construction process and its core points are shown in Figure 8.

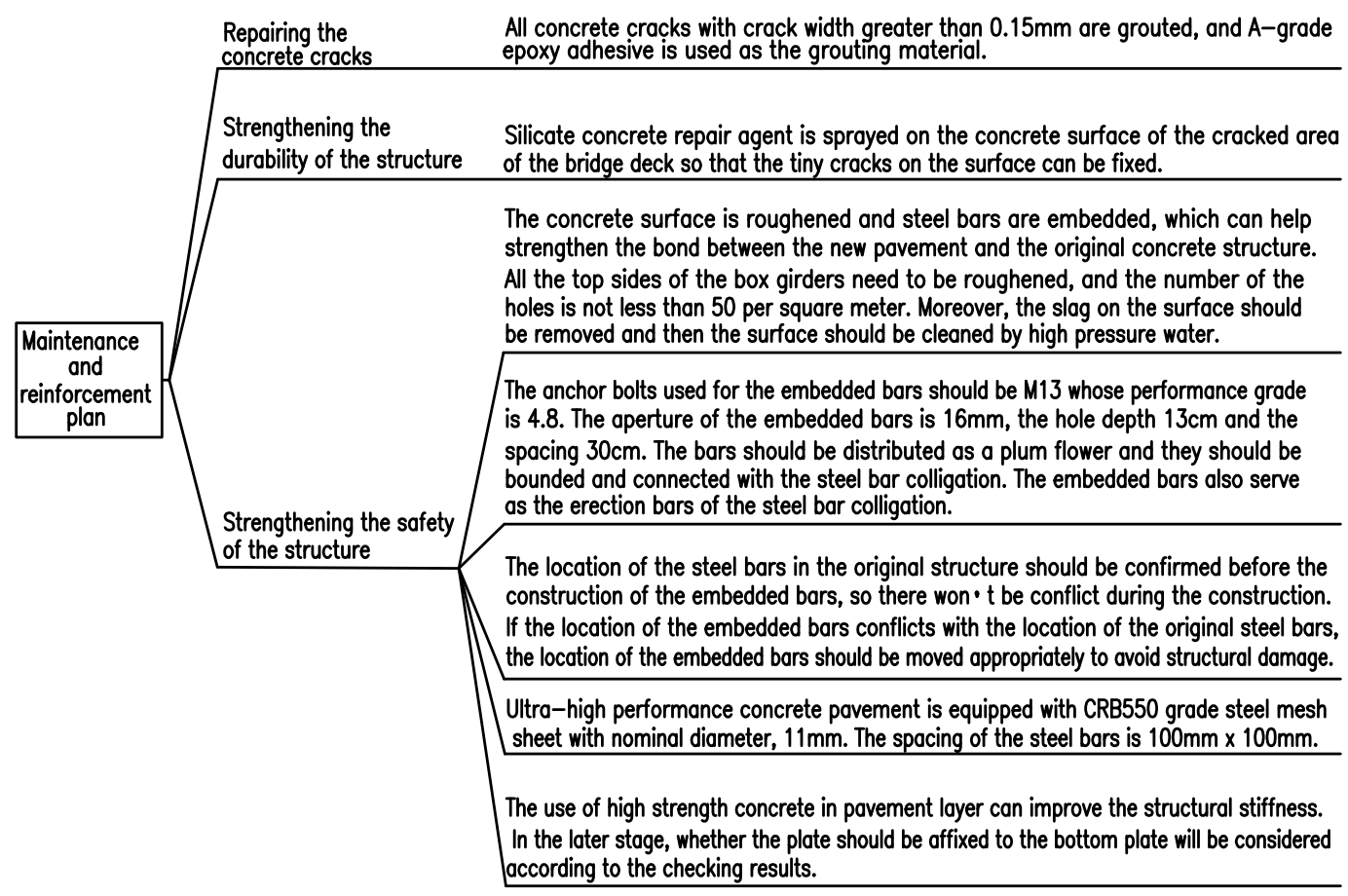

Figure 8. Flow Chart of the Plan and the Key of the Construction

\section{Conclusion}

Based on the investigation of the cracking status of the reinforced concrete box girders of the bridge, construction data and numerical simulation, the causes of the cracks in the box girders and their lingering effect were analyzed. Besides, the maintenance and reinforcement plan that UT10 ultra-high performance concrete should be used as the pavement material of the bridge deck was put forward, which realizes the simple and effective reinforcement and transformation on the cracks in the box girders. The technical idea and the strengthening methods mentioned in this paper can provide reference for the diagnosis and improvement of bridges with similar problems.

\section{Reference}

1. "General Code for Design of Highway Bridges and Culverts" (JTG D60-2015).
2. "Code for Design of Highway Reinforced Concrete and Pre-stressed Concrete Bridges and Culverts" (JTG3362-2018).

3. "Technical Code for Construction of Highway Bridges and Culverts" (JTG/T F50-2011).

4. Du Lingjun, Tao Haihong. Cause Analysis and Prevention and Control of Cracks in Pre-stressed Concrete Box Girder of Continuous Rigid Frame Bridge. Henan Building Materials, 2012(04): 42-44.

5. $\mathrm{Xu}$ Zhen, Zhang Xuesong, Xu Junlan. Influence Analysis of Parameters on Mid-Span Deflection of Continuous Rigid Frame. Journal of Chongqing Jiaotong University: Natural Science Edition, 2007,26(4):9-13.

6. Zhao Dianjun, Liu Congfeng. Analysis and Control of Construction Crack in Reinforced Concrete Box Girder. Technology News, 2019(15):680. 